\title{
Molecular mutations as a possible factor for determining extent of thyroid surgery
}

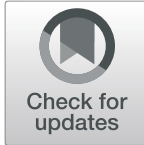

Joshua R. Krasner ${ }^{1 *}$, Nourah Alyouha ${ }^{2}$, Marc Pusztaszeri ${ }^{3}$, Veronique-Isabelle Forest ${ }^{2}$, Michael P. Hier ${ }^{2}$, Galit Avior ${ }^{4}$ and Richard J. Payne ${ }^{2}$ (I)

\begin{abstract}
Background: Molecular testing of thyroid nodules is a diagnostic tool used to better understand the nature of thyroid nodules. The aim of this study is to better comprehend the relationship between specific mutations and aggressive behavior of the tumour as demonstrated on postoperative pathological analysis.

Methods: A retrospective chart review of 103 cases was performed. Included were patients who had undergone molecular testing using a panel that tests for 9 mutations (ThyGenX $X^{\oplus}$ ) and were found to have malignant tumours. The following gene alterations were found pre-operatively in the nodules: BRAF V600E $(n=32), \operatorname{BRAF} K 601 E(n=4)$, NRAS $(n=11)$, HRAS $(n=4)$, KRAS $(n=3)$, RET/PTC1 rearrangement $(n=1)$, TERT promoter $(n=2)$, PAX8-PPARY rearrangement $(n=1)$, and 45 cases where no mutation was detected. Aggressive behavior was defined by extrathyroidal extension (ETE), lymph node metastasis $(\mathrm{LN}+)$, and the following variants of papillary thyroid carcinoma: tall cell, solid, diffuse sclerosing, columnar cell and hobnail. Chi-squared testing was performed to compare groups.

Results: The group with BRAF V600E, RET/PTC1 rearrangement, and TERT promoter mutations was associated with ETE $37.1 \%$, and $L N+45.7 \%$ of the time compared to 4.3 and $13.0 \%$ in the group with other mutations, and 4.4 and $4.4 \%$ in the group with no mutations ( $p$-value 0.02 , $p$-value $<0.001$, $p$-value 0.006). In addition, the BRAF V600E, RET/ PTC1 rearrangement, and TERT mutations group demonstrated tall cell variants (17.1\%), columnar cell variants (5.7\%), and hobnail variants (3\%). The other mutations group demonstrated columnar cell variants (4.3\%), and the no mutations group demonstrated solid variants (2.2\%).

Conclusions: In this study, BRAF V600E, RET/PTC1 rearrangement, and TERT mutations were associated with aggressive behaving thyroid malignancies as defined above. Molecular testing may be a useful method to anticipate aggressive tumour types and therefore assist in planning the extent and timing of surgery.
\end{abstract}

Keywords: Thyroid cancer, Molecular testing, Extent of surgery, BRAF V600E, TERT, RAS

\section{Background}

Current preoperative thyroid nodule evaluation strategies such as ultrasound $(\mathrm{U} / \mathrm{S})$ and fine needle aspiration (FNA) have been around since the 1970's. These modalities have improved diagnostic accuracy. Nevertheless, approximately $20-25 \%$ of thyroid nodules remain indeterminate after U/S and FNA, highlighting the need for more accurate testing [1]. Molecular testing of thyroid nodules is a diagnostic tool used to better understand

\footnotetext{
* Correspondence: josh.krasner@mail.mcgill.ca

${ }^{1}$ Faculty of Science, McGill University, 853 Sherbrooke Street West, Montreal, QC, Canada

Full list of author information is available at the end of the article
}

the nature of thyroid nodules, thereby improving patient care [2].

Studies have attributed certain tumour characteristics/ behaviours with specific mutations.

The oncogenic BRAF V600E mutation occurs in about $40-45 \%$ of papillary thyroid cancers (PTC). It activates the MAPK signaling pathway in human cancer and has been shown to correlate with aggressive features in PTC, including extrathyroidal extension (ETE), lymph node metastasis $(\mathrm{LN}+)$, and the tall cell variant [3]. An increasing number of studies that include meta-analyses have been able to demonstrate an association between BRAF V600E status and aggressive tumour behavior [49]. Other studies, however, could not confirm this data,

(c) The Author(s). 2019 Open Access This article is distributed under the terms of the Creative Commons Attribution 4.0 International License (http://creativecommons.org/licenses/by/4.0/), which permits unrestricted use, distribution, and 
which has resulted in uncertainty about the value of BRAF V600E in PTC [10-15]. BRAF V600E mutations have also been shown to have more aggressive features on pre-operative US [16].

Activation of the telomerase reverse transcriptase (TERT) gene, which encodes for the catalytic subunit of telomerase, is implicated in tumorigenesis and cell immortalization. TERT promoter mutations were recently reported in thyroid cancer $[17,18]$ where they have been associated with aggressive cancers [17].

$R A S$ mutations on the other hand may be more indolent with one study showing that they are related to more encapsulated tumours and lower rates of lymph node metastasis [1]. RAS mutations are also present in benign follicular adenomas [3].

The aim of this study was to investigate whether there is a relationship between molecular mutations tested for by ThyGenX: BRAF V600E, BRAF K601E, HRAS, NRAS, KRAS, TERT, PAX8-PPARY, RET/PTC1, RET/PTC3, $P I K 3 C A$ and aggressive post-operative features on pathological analysis.

\section{Methods}

\section{Study design}

This is a retrospective chart review of 103 medical charts performed at a McGill University Teaching Hospital in Montreal, Quebec. Data on baseline characteristics, results of molecular mutation testing and postoperative pathology was collected. The specific type of malignancy (papillary thyroid carcinoma, follicular carcinoma, hurthle cell carcinoma, poorly differentiated thyroid carcinoma) and the specific variant (classical, follicular, oncocytic, tall cell, columnar cell, solid, hobnail) were recorded. Noninvasive follicular thyroid neoplasm with papillary-like nuclear features (NIFTP) tumors were recorded as well (Table 1). See Additional file 1 for all data collected. Aggressive tumours were defined as having at least one of the following features: ETE, LN+ or any of the following variants of papillary thyroid carcinoma (tall cell, solid, diffuse sclerosing, columnar cell, hobnail) as per the postoperative pathology report. This study (CR17-52) was approved by the Research Ethics Committee at the Jewish General Hospital, Montreal, Quebec.

\section{Patient selection}

The charts of patients who underwent pre-operative molecular testing using ThyGenX ${ }^{\bullet}$ from January 2016 to February 2018 were reviewed. Patients who had surgery and confirmed thyroid malignancy of the nodule that underwent molecular testing were included in this study. Patients with benign tumours on final pathology or who had undergone molecular testing using other testing methods were excluded. Patients were divided into three groups. The first group consisted of patients that tested positive for BRAF V600E, RET/PTC1 rearrangement, or TERT promoter mutations [19]. The second group consisted of patients that tested positive for BRAF K601E, HRAS, NRAS, KRAS, and PAX8-PPARY rearrangement. The third group consisted of patients where no mutation was detected on molecular testing.

\section{Sample collection}

After obtaining informed consent from the patient, ultrasound guided FNA was performed to collect the thyroid nodule sample for molecular testing. The specimen was then added to RNARetain ${ }^{\circ}$ (a preservative solution), after which the sample was transported at room temperature via courier to Interpace Diagnostics in Pittsburgh, United States.

The surgical pathology specimens were reported by experienced thyroid pathologists who routinely comment on aggressive features as defined by: tumours with ETE, $\mathrm{LN}+$, and the following variants of papillary thyroid cancer: tall cell, solid type, diffuse sclerosing, columnar cell, and hobnail.

Table 1 Histological types

\begin{tabular}{|c|c|c|c|c|c|c|c|c|}
\hline & BRAF V600E & BRAF K601E & RAS & RET/PTC1 & TERT & PAX8-PPAR $_{Y}$ & No Mutation & Total \\
\hline \multicolumn{9}{|l|}{ Papillary carcinoma } \\
\hline Classical & 22 & 0 & 1 & 1 & 0 & 0 & 17 & 41 \\
\hline Follicular & 3 & 4 & 13 & 0 & 1 & 1 & 13 & 35 \\
\hline Oncocytic & 0 & 0 & 0 & 0 & 0 & 0 & 4 & 4 \\
\hline Tall cell & 4 & 0 & 0 & 0 & 1 & 0 & 0 & 5 \\
\hline Columnar cell & 2 & 0 & 1 & 0 & 0 & 0 & 0 & 3 \\
\hline Solid & 0 & 0 & 0 & 0 & 0 & 0 & 1 & 1 \\
\hline Hobnail & 1 & 0 & 0 & 0 & 0 & 0 & 0 & 1 \\
\hline Follicular carcinoma (Minimally invasive) & 0 & 0 & 0 & 0 & 0 & 0 & 4 & 4 \\
\hline Hurthle cell carcinoma & 0 & 0 & 0 & 0 & 0 & 0 & 1 & 1 \\
\hline NIFTP & 0 & 0 & 3 & 0 & 0 & 0 & 5 & 8 \\
\hline
\end{tabular}




\section{Statistical analysis}

One-way ANOVA was performed to compare groups. If a statistical significance was suspected an ad-hoc analysis using Dunnet's-T3 was performed to determine $p$-value. Significance was confirmed at a $p$ value $<0.05$. Relative risk calculations were performed using SPSS software.

\section{Results}

\section{Baseline characteristics}

A total of 103 charts were included in this study. Baseline information was calculated for each tumour. This included age, gender, the longest axis measurement in centimeters $(\mathrm{cm})$ of the tumour as per the postoperative pathology report, the longest axis measurement in $\mathrm{cm}$ of the tumour as per the pre-operative $\mathrm{U} / \mathrm{S}$ assessment, and the ultrasound guided FNA biopsy results using the Bethesda classification or interpreted Bethesda classification using cellblock technique or cytospin analysis. The baseline characteristics of each group is summarised in Table 2 . No statistically significant differences were detected with regards to age and gender. Apart from TERT promoter mutated tumours, which were found to be statistically larger than $B R A F$ $K 601 E$ mutated tumours $(p<0.05)$, there were no differences with regards to tumour size.

Group 1 (BRAF V600E, RET/PTC1, and TERT) consisted of 35 nodules. Group 2 (NRAS, HRAS, KRAS, BRAF K601E, and PAX8-PPARY) consisted of 23 nodules. Group 3 (no mutation detected) consisted of 45 nodules. Group 1 demonstrated a statistically significant increase in the proportion of tumours displaying aggressive features (65.7\% of the nodules) when compared to Group 2 which demonstrated aggressive features in $21.7 \%$ of the nodules, and Group 3 which demonstrated aggressive features in $11.1 \%$ of the nodules ( $p$-value < 0.01) (Fig. 1).

The tumours in Group 1 demonstrated the following on final pathology: ETE in 11.4\% $(n=4)$, micro ETE in $25.7 \%(n=9), \mathrm{LN}+$ in $45.7 \%(n=16)$, tall cell variant in
17.1\% $(n=6)$, columnar cell variant in $5.7 \%(n=2)$, and hobnail variant in $2.9 \%(n=1)$. In comparison, the tumours in Group 2 demonstrated: micro ETE in 4.3\% $(n=1), \mathrm{LN}+$ in $13 \%(n=3)$, and columnar cell variant in 4.3\% $(n=1)$. The tumours in Group 3 demonstrated: micro ETE in $4.4 \%(n=2), \mathrm{LN}+$ in $4.4 \%(n=2)$, and solid variant in $2.2 \%(n=1)$ (Fig. 2$)$.

\section{Aggressive features for specific mutations}

The number of aggressive features within each tumour was compared. This demonstrated that BRAF $V 600 E$ tumours were more likely to express multiple aggressive features when compared to $R A S$ and tumours where no mutation was detected. BRAF V600E was the only mutation in which more than 1 aggressive feature within one tumour was present. These findings are demonstrated in Fig. 3. It is worth noting that the number of tumours exhibiting BRAF K601E, TERT, RET/PTC1, and PAX8-PPARY were too low to establish statistical significance.

BRAF V600E tumours were 5.91 times (relative risk) more likely to demonstrate aggressive features when compared to tumours where no mutation was detected (95\% CI 2.49-14.0, $p$-value 0.0001). Supplemental Figure 1 illustrates one of these cases (Fig. 4). Furthermore, BRAF V600E tumours were 2.49 times more likely to demonstrate aggressive features when compared to tumours where a RAS mutation was detected $(95 \% \mathrm{CI}$ 1.13-5.51, $p$-value 0.024). RAS mutations were not found to be statistically more likely to demonstrate aggressive features when compared to tumours with no mutation detected $(\mathrm{RR}=2 ; 95 \% \mathrm{CI} 0.6-6.61, p$ value 0.26$)$. The relative risk of aggressive features is summarized in Table 3.

\section{Discussion}

Molecular testing is a diagnostic tool that is used to better understand the nature of thyroid nodules preoperatively. Much of the literature has focused on

Table 2 Baseline characteristics

\begin{tabular}{|c|c|c|c|c|c|c|c|c|c|}
\hline \multirow[t]{2}{*}{ Mutation } & \multirow[t]{2}{*}{$n$} & \multirow[t]{2}{*}{$\begin{array}{l}\text { Mean } \\
\text { age }\end{array}$} & \multirow[t]{2}{*}{$\begin{array}{l}\text { Gender } \\
\text { (F:M) }\end{array}$} & \multirow[t]{2}{*}{$\begin{array}{l}\text { Mean final } \\
\text { pathology size }(\mathrm{cm})\end{array}$} & \multirow[t]{2}{*}{$\begin{array}{l}\text { Mean U/S } \\
\text { size }(\mathrm{cm})\end{array}$} & \multicolumn{4}{|c|}{$\begin{array}{l}\text { FNA } \\
\text { bethesda score distribution (\%) }\end{array}$} \\
\hline & & & & & & $\mathrm{Vl}$ & V & IV & III \\
\hline BRAF V600E & 32 & 46.53 & 1.21 & 1.70 & 1.8 & 87 & 13 & 0 & 0 \\
\hline BRAF K601E & 4 & 47.00 & 1.5 & $1.08^{*}$ & 1.2 & 0 & 75 & 25 & 0 \\
\hline RAS & 18 & 45.83 & 1.33 & 2.38 & 2.4 & 28 & 33 & 11 & 28 \\
\hline TERT & 2 & 67.00 & 1 & $2.80^{*}$ & 2.1 & 50 & 0 & 50 & 0 \\
\hline RET/PTC1 & 1 & 46.00 & 1 & 1.50 & 1.80 & 100 & 0 & 0 & 0 \\
\hline PAX8/PPARY & 1 & 51.96 & 0 & 1.00 & 1.40 & 0 & 0 & 100 & 0 \\
\hline No mutations & 45 & 51.96 & 1.31 & 1.85 & 2.2 & 29 & 38 & 22 & 11 \\
\hline
\end{tabular}




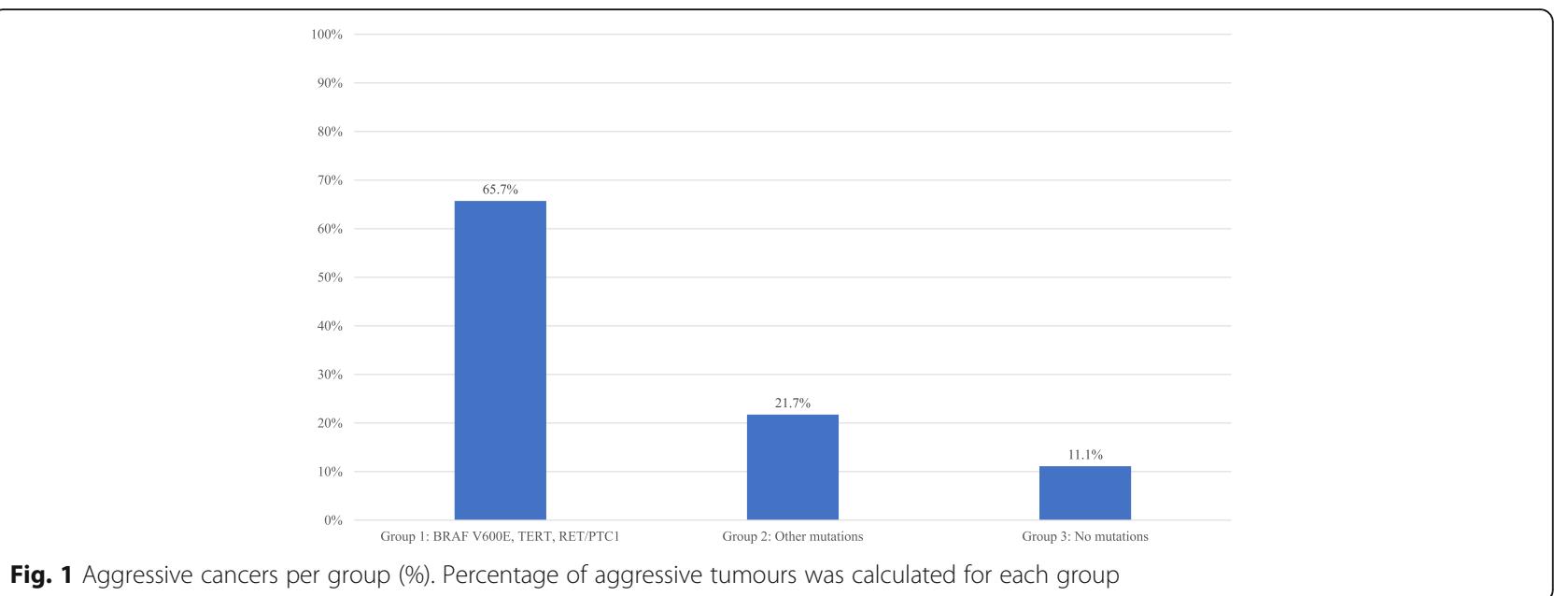

molecular testing's ability to determine whether a patient with an indeterminate thyroid nodule requires surgery $[2,3,20-23]$. Our study's aim was to take the analysis one step further and to determine whether molecular testing can help with decisionmaking on the optimal surgical treatment, including the extent and timing of surgery for patients with a thyroid nodule that was suspicious or malignant on thyroid FNA.

Total thyroidectomy is associated with a higher risk of surgical complications and requires patients to take lifelong hormone replacement therapy. Patients undergoing hemithyroidectomy require completion thyroidectomy at times [24]. Therefore, selecting the appropriate initial surgical procedure improves patient care and saves the health care system valuable resources.
In this study, BRAF V600E, RET/PTC1 rearrangement, and TERT promoter mutations were found to be associated with aggressive cancers $65.7 \%$ of the time. In comparison, $21.7 \%$ of nodules that preoperatively tested positive for BRAF K601E, HRAS, NRAS, $K R A S$, or PAX8-PPARY rearrangement mutations and $11.1 \%$ of nodules where no mutation was detected were found to have aggressive features in the postoperative pathology report $(n=103, p<0.01)$. Similar findings in microcarcinomas have recently been reported [25]. This finding demonstrates the clinical validity of molecular testing as outlined by the 2015 American Thyroid Association Guidelines by successfully distinguishing different groups of patients based on expected disease outcome (likelihood of recurrence). In addition to guiding the decision of the extent of surgery, the association of certain mutations

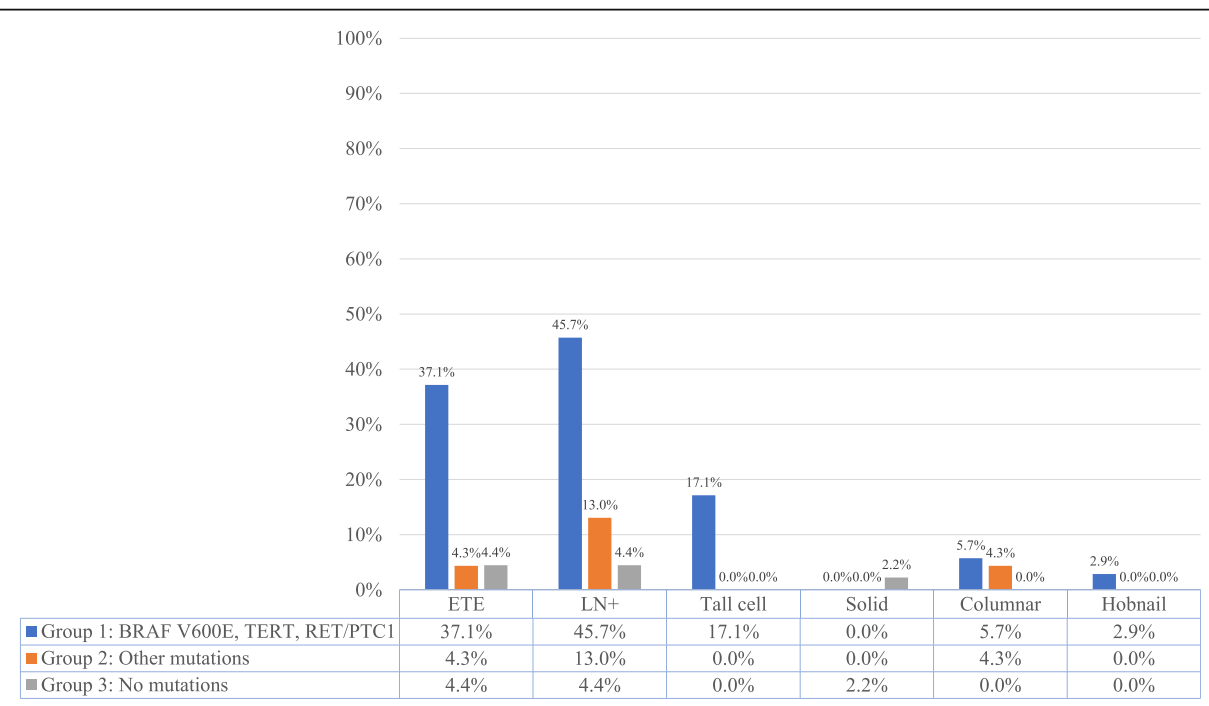

Fig. 2 Aggressive features per group (\%). Percentage of individual aggressive features in each group was calculated 

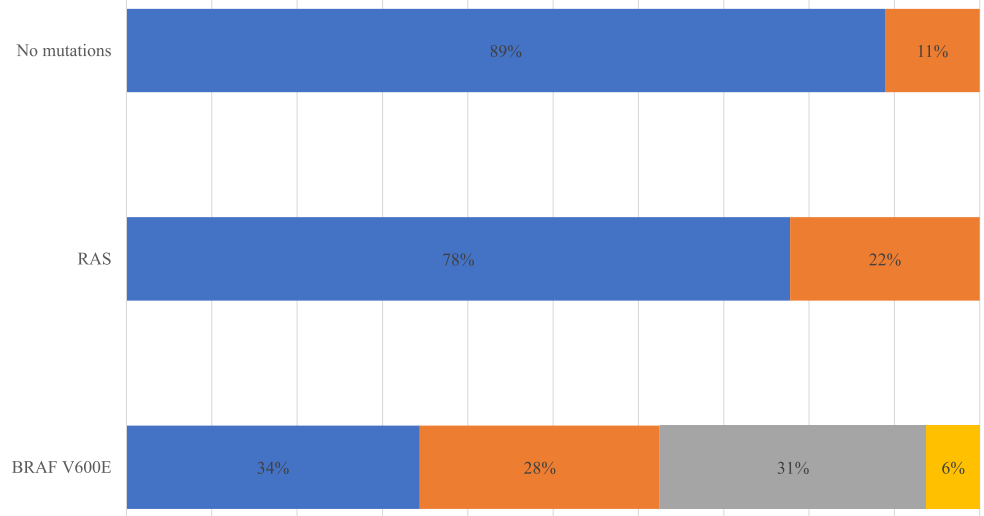

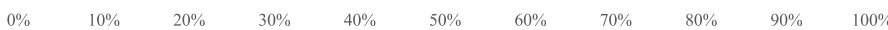

Fig. 3 Number of aggressive features per mutation (\%). Tumours were stratified in groups that either demonstrated no aggressive features, 1, 2, or 3 aggressive features

with aggressivity may allow the test to guide the timing of surgery.

There are several limitations in this study, including the inherent limitations of a retrospective study. As a single center study in Montreal, Canada, a geographic selection bias was introduced. Furthermore, since molecular testing is not available at most Canadian centers, a selection bias for patients who had access to the test was also introduced. Also, the molecular test that was used is a limited panel, as a result, there are mutations and genetic alterations that are not being detected. Finally, surgeons and pathologists were not blinded to

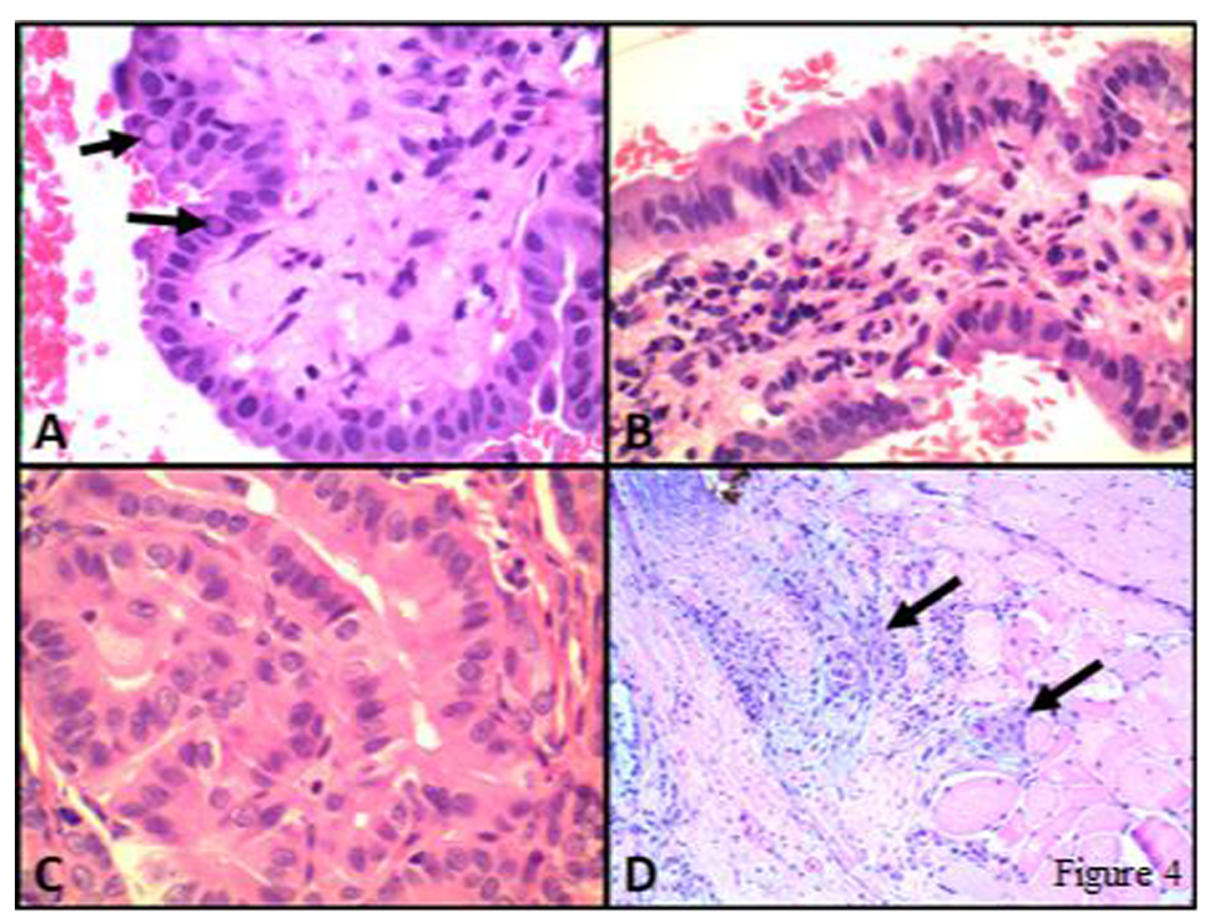

Fig. 4 Photomicrographs from a case of PTC, tall cell variant. In this case, tall cell features (i.e. tumour cells 2 or 3 times taller than wide) were present both on the FNA material $\mathbf{a}$ and $\mathbf{b}$, Cell block, H\&E), which was classified as Malignant-PTC (Bethesda VI), and on the corresponding resection specimen (c and $\mathbf{d}, \mathrm{H} \&$ E). The tumour cells also show classical nuclear features of PTC including several intranuclear pseudoinclusions (arrows in A). Extrathyroidal extension was present (D, H\&E) with several clusters of tumour cells (arrows) invading skeletal muscle. Molecular testing revealed BRAF V600E mutation 
Table 3 Relative Risk of Aggressive Features

\begin{tabular}{llll}
\hline Mutation & BRAF V600E Relative Risk & $95 \% \mathrm{Cl}$ & $p$-value \\
\hline No mutation & 5.91 & $2.49-14.0$ & $0.0001^{*}$ \\
RAS & 2.49 & $1.13-5.51$ & $0.024^{*}$ \\
\hline
\end{tabular}

*Statistically significant $\mathrm{p}$-value $<0.05$

the results of molecular testing. Future studies should involve a more comprehensive molecular testing panel, a double blinded and multicenter approach, with financial aid, to minimize these limitations.

\section{Conclusions}

In this study, BRAF V600E, RETPTC1 rearrangement, and TERT promoter mutations were found to be associated with more aggressive cancers when compared to malignancies without one of these mutations. This association demonstrates that molecular testing may be a valuable pre-operative tool to help guide the decision as to the extent of surgery, hemi-thyroidectomy versus total thyroidectomy and possible central compartment neck dissection, although further prospective studies with larger sample sizes are needed. Choosing the optimal extent of surgery will lead to improved patient care and save the health care system valuable resources.

\section{Supplementary information}

Supplementary information accompanies this paper at https://doi.org/10. 1186/s40463-019-0372-5

Additional file 1. Krasner et al. raw data bank.

\section{Abbreviations}

ETE: Extra-Thyroidal Extension; FNA: Fine Needle Aspiration; LN + : Lymph Node Metastasis; U/S: Ultrasound

\section{Acknowledgements}

Not applicable.

\section{Authors' contributions}

The original idea was conceived and the study was designed by RP. JK and NA were responsible for creating and completing the database. The original manuscript was created by JK and was reviewed and approved by all authors. JK, RP, VF, GA, MH, GA, and NA all made valuable contributions and changes to the manuscript leading to its completion. All authors read and approved the final manuscript.

\section{Funding}

No sources of funding to declare.

\section{Availability of data and materials}

The dataset supporting the conclusions of this article is included within the article (and its additional files.)

\section{Ethics approval and consent to participate}

This study (CR17-52) was approved by the Research Ethics Committee at the Jewish General Hospital, Montreal, Quebec.

\section{Consent for publication}

Not applicable.

\section{Competing interests}

No competing financial or non-financial interests exist.

\section{Author details}

${ }^{1}$ Faculty of Science, McGill University, 853 Sherbrooke Street West, Montreal, QC, Canada. ${ }^{2}$ Department of Otolaryngology Head and Neck Surgery, Sir Mortimer B. Davis-Jewish General Hospital, McGill University, Montreal, QC, Canada. ${ }^{3}$ Department of Pathology, Sir Mortimer B. Davis-Jewish General Hospital, McGill University, Montreal, QC, Canada. ${ }^{4}$ Department of Otolaryngology Head and Neck Surgery, Technion, Faculty of Medicine, Hillel-Yaffe Medical Center, Hadera, Israel.

Received: 9 April 2019 Accepted: 9 September 2019

Published online: 17 October 2019

\section{References}

1. Patel SG, Carty SE, McCoy KL, Ohori NP, LeBeau SO, Seethala RR, Nikiforova MN, Niiforov YE, Yip L. Preoperative detection of RAS mutation may guide extent of thyroidectomy. Surgery. 2017;161:168-75.

2. Haugen BR, Alexander EK, Bible KC, Doherty GM, Mandel SJ, Nikiforov YE, Pacini F, Randolph GW, Sawka AM, Schlumberger M, Schuff KG, Sherman SI, Sosa JA, Steward DL, Tuttle MR, Wartofsky L. 2015 American Thyroid Association management guidelines for adult patients with thyroid nodules and differentiated thyroid Cancer: the American Thyroid Association guidelines task force on thyroid nodules and differentiated thyroid Cancer. Thyroid. 2016;26:1-133.

3. Nikiforov YE. Molecular analysis of thyroid tumours. Mod Pathol. 2011:24:34-43.

4. Kim TH, Park YJ, Lim JA, Ahn HY, Lee EK, Lee YJ, Kim KW, Hahn SK, Youn YK, Kim KH, Cho BY, Park DJ. The association of the BRAF(V600E) mutation with prognostic factors and poor clinical outcome in papillary thyroid cancer: a meta-analysis. Cancer. 2012;118:1764-73.

5. Xing M. Molecular pathogenesis and mechanisms of thyroid cancer. Nat Rev Cancer. 2013;13:184-99.

6. Elisei R, Viola D, Torregrossa L, Giannini R, Romei C, Ugolini C, Molinaro E, Agate L, Biagini A, Lupi C, Valerio L, Materazzi G, Miccoli P, Piaggi P, Pinchera A, Vitti P, Basolo F. The BRAF(V600E) mutation is an independent, poor prognostic factor for the outcome of patients with low-risk Intrathyroid papillary thyroid carcinoma: single-institution results from a large cohort study. J Clin Endocrinol Metab. 2012;97:4390-8.

7. Li C, Lee KC, Schneider EB, Zeiger MA. BRAF V600E mutation and its association with clinicopathological features of papillary thyroid cancer: a meta-analysis. J Clin Endocrinol Metab. 2012;97:4559-70.

8. Chen Y, Sadow PM, Suh H, Lee KE, Choi JY, Suh YJ, Wang TS, Lubitz CC. BRAF(V600E) is correlated with recurrence of papillary thyroid microcarcinoma: a systematic review, multi institutional primary data analysis, and meta-analysis. Thyroid. 2016;26:248-55.

9. Biron VL, Matkin A, Kostiuk M, Williams J, Cote DW, Harris J, Seikaly H, O'Connell DA. Analytic and clinical validity of thyroid nodule mutational profiling using droplet digital polymerase chain reaction. J Otolaryngol Head Neck Surg. 2018;47:60.

10. Ito Y, Yoshida H, Maruo R, Morita S, Takano T, Hirokawa M, Yabuta T, Fukushima M, Inoue H, Tomoda C, Kihara M, Uruno T, Higashiyama T, Takamura Y, Miya A, Kobayashi K, Matsuzuka F, Miyauchi A. BRAF mutation in papillary thyroid carcinoma in a Japanese population: its lack of correlation with high-risk clinicopathological features and disease-free survival of patients. Endocr J. 2009;56:89-97.

11. Cheng S, Serra S, Mercado M, Ezzat S, Asa SL. A high-throughput proteomic approach provides distinct signatures for thyroid Cancer behavior. Clin Cancer Res. 2011;17:2385-94.

12. Eloy C, Santos J, Soares P, Sobrinho-Simoes M. The preeminence of growth pattern and invasiveness and the limited influence of BRAF and RAS mutations in the occurrence of papillary thyroid carcinoma lymph node metastases. Virchows Arch. 2011;459:265-76.

13. Koperek O, Kornauth C, Capper D, Berghoff AS, Asari R, Niederle B, von Deimling A, Birner P, Preusser M. Immunohistochemical detection of the BRAF V600E-mutated protein in papillary thyroid carcinoma. Am J Surg Pathol. 2012;36:844-50.

14. Sancisi V, Nicoli D, Ragazzi M, Piana S, Ciarrocchi A. BRAFV600E mutation does not mean distant metastasis in thyroid papillary carcinomas. J Clin Endocrinol Metab. 2012;97:1745-9.

15. Barbaro D, Incensati RM, Materazzi G, Boni G, Grosso M, Panicucci E, Lapi P, Pasquini C, Miccoli P. The BRAF V600E mutation in papillary thyroid cancer with positive or suspected pre-surgical cytological finding is not associated with advanced stages or worse prognosis. Endocrine. 2014;45:462-8. 
16. Wang S, Liu Z, Sun S, Li X, Zeng W, Xiong Y, Guo Y, Wang J, Wang Y, Liu C, Huang TX. Ultrasound features suspicious for malignancy predict the risk of BRAF mutation in papillary thyroid carcinoma. Int J Clin Exp Med. 2014;10:9470-5.

17. Liu X, Bishop J, Shan Y, Pai S, Liu D, Murugan AK, Sun H, El-Naggar AK, Xing M. Highly prevalent TERT promoter mutations in aggressive thyroid cancers. Endocr Relat Cancer. 2013;20:603-10.

18. Vinagre J, Almeida A, Pópulo H, Batista R, Lyra J, Pinto V, Coelho R, Celestino R, Prazeres H, Lima L, Melo M, da Rocha AG, Preto A, Castro P, Castro L, Pardal F, Lopes JM, Santos LL, Reis RM, Cameselle-Teijeiro J, SobrinhoSimões M, Lima J, Máximo V, Soares P. Frequency of TERT promoter mutations in human cancers. Nat Commun. 2013:4:2185.

19. Cancer Genome Atlas Research Network. Integrated genomic characterization of papillary thyroid carcinoma. Cell. 2014;159(3):676-90. https://doi.org/10.1016/j.cell.2014.09.050.

20. Nishino M. Molecular cytopathology for thyroid nodules: a review of methodology and test performance. Cancer Cytopathol. 2016;124:14-27.

21. Najafian A, Noureldine S, Azar F, Atallah C, Trinh G, Schneider EB, Tufano RP, Zeiger MA. RAS mutations, and RET/PTC and PAX8/PPAR-gamma chromosomal rearrangements are also prevalent in benign thyroid lesions: implications thereof and a systematic review. Thyroid. 2017;27:39-48.

22. Vargas-Salas S, Martínez JR. Urra1 S, Domínguez JM, Mena N, Uslar T, Lagos M, Henríquez M, González HE. Genetic testing for indeterminate thyroid cytology: review and meta-analysis. Endocr-Relat. Cancer. 2018;25:163-77.

23. Vuong HG, Duong UN, Altibi AM, Ngo HTT, Pham TQ, Tran HM, Gandolfi G, Hassell L. A meta-analysis of prognostic roles of molecular markers in papillary thyroid carcinoma. Endocr Connect. 2017:6(3):R8-R17.

24. Dobrinja C, Trevisan G, Piscopello L, Fava M, Liguori G. Comparison between thyroidectomy and hemithyroidectomy in treatment of single thyroid nodules identified as indeterminate follicular lesions by fine-needle aspiration cytology. Ann Ital Chir. 2010;81:403-10.

25. Zhou C, Li J, Wang Y, Xue S, Zhang Y. Association of BRAF gene and TSHR with cervical lymph node metastasis of papillary thyroid microcarcinoma. Oncol Lett. 2019:17:183-94.

\section{Publisher's Note}

Springer Nature remains neutral with regard to jurisdictional claims in published maps and institutional affiliations.

Ready to submit your research? Choose BMC and benefit from:

- fast, convenient online submission

- thorough peer review by experienced researchers in your field

- rapid publication on acceptance

- support for research data, including large and complex data types

- gold Open Access which fosters wider collaboration and increased citations

- maximum visibility for your research: over $100 \mathrm{M}$ website views per year

At $\mathrm{BMC}$, research is always in progress.

Learn more biomedcentral.com/submissions 